\title{
VER, NÃO VER E APRENDER: A PARTICIPAÇÃO DE CRIANÇAS COM BAIXA VISÃO E CEGUEIRA NA ESCOLA
}

\author{
Adriana Lia Friszman de Laplane* \\ Cecília Guarneiri Batista*
}

\begin{abstract}
RESUMO: Tomando como ponto de partida as teorias que compreendem os processos de desenvolvimento humano enquanto processos sociais, o presente artigo discute o desenvolvimento e a aprendizagem de crianças com deficiência visual, seus modos de apreensão do mundo e o uso de recursos para auxiliar na participação escolar. Trata-se de integrar, na prática pedagógica inclusiva, tanto a compreensão dos processos gerais de desenvolvimento como os aspectos particulares que a deficiência visual implica, de modo que seja possível agenciar os recursos necessários para a participação escolar plena.
\end{abstract}

Palavras-chave: Educação inclusiva. Práticas de inclusão na escola. Deficiência visual. Interação social. Recursos de ensino.

TO SEE, NOT TO SEE AND TO LEARN:

THE PARTICIPATION OF LOW VISION AND BLIND CHILDREN AT SCHOOL

ABSTRACT: Taking as point of departure the theories that understand the developmental processes as social, this paper discusses the development and learning processes of children with visual impairments, their modes of apprehension of the world and the use of resources to aid school participation. It focuses on the ways of integrating within the school practices, the understanding of the more general

* Doutora em Educação e docente da Faculdade de Ciências Médicas (CEPRE) da Universidade Estadual de Campinas (UNICAMP). E-mail: adrifri@fcm.unicamp.br

** Doutora em Psicologia e docente da Faculdade de Ciências Médicas (CEPRE) da UNICAMP. E-mail: cecigb@fcm.unicamp.br 
processes of human development, as well as the particular aspects related to visual impairments, to turn possible to allocate the resources needed to guarantee a full participation at school.

Key words: Inclusive education. Inclusive practices at school. Visual impairment. Social interaction. Learning resources.

\section{Introdução}

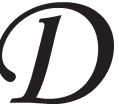

e que modo a deficiência visual interfere no desenvolvimento e na aprendizagem? Como ensinar alunos com deficiência visual? Qual é o lugar dos recursos pedagógicos e dos auxílios na sala de aula? Como escolher o recurso indicado para cada situação?

Essas perguntas surgem, muitas vezes, quando os professores se deparam com alunos com deficiência visual na sala de aula e, para respondê-las, é preciso primeiramente compreender que a deficiência visual engloba uma variedade de condições orgânicas e sensoriais que têm conseqüências diferentes no desempenho visual dos sujeitos. A deficiência visual compreende desde pequenas alteraçôes na acuidade visual até a ausência de percepção de luz, mas as alterações que têm implicações mais sérias para a vida das pessoas com necessidades especiais e para as suas famílias são a baixa visão e a cegueira.

A pessoa com baixa visão ou visão subnormal apresenta uma redução na sua capacidade visual que interfere ou limita seu desempenho, mesmo após a correção de erros de refração comuns. A baixa visão pode ocorrer por traumatismos, doenças ou imperfeiçōes no órgão ou no sistema visual. Um dos seus traços principais é a diversidade de problemas visuais que ela pode gerar. As pessoas com baixa visão podem ter baixa acuidade visual, dificuldade para enxergar de perto e/ou de longe, campo visual reduzido e problemas na visão de contraste, entre outros (Carvalho et al., 1992; Veitzman, 2000).

A cegueira ocorre quando a visão varia de zero (ausência de percepção de luminosidade) a um décimo na escala optométrica de Snellen, ou quando o campo visual é reduzido a um ângulo menor que 20 graus. Para além dos termos técnicos e das medidas de acuidade visual é importante entender que entre as pessoas com baixa visão e cegueira podemos encontrar situações muito díspares. Algumas dessas pessoas terão autonomia na locomoção e outras deverão desenvolver estratégias para 
atingi-la; algumas poderão realizar com pouca dificuldade as tarefas escolares sem qualquer auxílio e outras necessitarão de auxílios ópticos (lupas e telescópios) ou não ópticos (ampliações, iluminação especial e outras adaptações do ambiente) para melhorar seu desempenho; algumas conseguirão utilizar materiais visuais e outras preferirão os materiais táteis (sistema Braille de escrita) ou auditivos. À diversidade natural existente na natureza humana soma-se, assim, a variabilidade das condiçóes criadas pelos diferentes tipos de deficiência visual e seus efeitos no desenvolvimento e na comunicação com os outros.

\section{Desenvolvimento e aprendizagem}

Como a criança com baixa visão ou cegueira se desenvolve e aprende? O que é comum e o que é diferente nos processos de desenvolvimento e aprendizagem que crianças com e sem deficiência visual atravessam? Essas questôes são cruciais para definir o tipo de intervenção pedagógica indicada para esses alunos. As concepções de desenvolvimento e de aprendizagem norteiam, de um modo geral, todo o trabalho educacional e, por isso, é importante retomar aqui algumas idéias sobre desenvolvimento e aprendizagem. As teorias de desenvolvimento admitem, hoje, que este é a conseqüência de um conjunto de fatores genéticos e ambientais que se configuram de maneira única em cada sujeito. Para algumas teorias como a de Vigotski (1984), os fatores ambientais e dentro desses os sociais e culturais, condensados na função da linguagem, são fundamentais nos processos de desenvolvimento e aprendizagem. Na idéia de que o homem é um ser social está embutida a de que o homem se desenvolve na sociedade e na cultura, por meio de uma ferramenta especialmente desenvolvida para isso, isto é, o homem é um ser capaz de aprender com o outro por meio da linguagem que organiza e dá sentido à experiência humana compartilhada. Dessa idéia decorre a de que o desenvolvimento e a aprendizagem ocorrem no espaço privilegiado constituído pelas relaçóes sociais, no espaço em que os seres humanos interagem entre si e com os objetos do mundo. Em contrapartida, é possível descrever o que ocorre no nível dos sentidos, do corpo e do cérebro e tudo isso é certamente importante para o desenvolvimento humano, mas, em geral é difícil interferir nesses níveis (a não ser por meio de procedimentos médicos, principalmente). Enquanto isso, o que ocorre no espaço das relaçóes interativas pode ser alterado, de modo que essa dimensão se torna especialmente interessante para a ação 
pedagógica porque permite ao professor agenciar as situações de ensino de forma colaborativa com os alunos. $\mathrm{Na}$ mesma perspectiva, o psicólogo americano J. Bruner (1997, p. 30), ao discutir as relaçōes entre cultura e biologia, destaca o papel da cultura no desenvolvimento: “(...) a cultura e a busca por significados são a mão modeladora, a biologia é a restrição e, conforme vimos, cabe à cultura deter o poder de afrouxar essas limitações".

Partindo da premissa de que "é a cultura, e não a biologia, que molda a vida e a mente humanas, que dá significado à ação” (p. 40), Bruner nos ajuda a pensar as formas em que a cultura e as relaçóes sociais podem modificar e transcender as limitações impostas pela biologia. Desse modo, uma parte do desenvolvimento humano pode ser entendida como o produto do trabalho escolar, e este pode ser pensado no contexto das relaçôes que se criam entre quem aprende, quem ensina e o objeto de aprendizagem. Essas concepçôes de desenvolvimento e de aprendizagem permitem compreender os processos psicológicos como processos compartilhados por todos. Elas fundamentam, de um modo geral, o trabalho escolar, marcando os rumos e ajudando a adequar os objetivos e os meios de alcançá-los.

Entretanto, a própria ênfase que se dá às relações, à linguagem e à cultura na compreensão dos processos de desenvolvimento e aprendizagem faz com que as características próprias de grupos ou mesmo de indivíduos sejam levadas em consideração para planejar e implementar ações pedagógicas. Assim, no caso de alunos com deficiência visual será preciso considerar, dentro dos processos gerais comuns a todos os indivíduos que aprendem, as particularidades que singularizam esses processos.

\section{O desenvolvimento de crianças com deficiência visual}

Ao nascer, a criança estabelece uma relação inicial com o mundo social por meio do vínculo com a mãe ou com o adulto por quem é cuidada. Todas as vertentes teóricas coincidem na atribuição de grande importância a esse vínculo inicial que constitui a matriz sobre a qual serão construídos sentidos e significados por meio da linguagem e da ação mediada. As percepções tátil, olfativa, visual e auditiva são as vias de acesso da informação que provêm desse mundo social que se apresenta ao 
recém-nascido como fonte do alimento, segurança e bem-estar. Dentre os sentidos, o da visão tem papel importante na configuração do vínculo. O contato visual é uma das formas em que mãe e filho estabelecem relações. O que fazer quando a criança não devolve o olhar da mãe? Se ela não enxerga ou enxerga tão pouco que a qualidade da visão torna desinteressante a atividade de olhar, como ela aprenderá a imitar? Como ela terá a percepção do que acontece em volta dela? A deficiência visual será responsável por alterações ou atrasos no desenvolvimento?

As pesquisas que comparam o desenvolvimento de bebês cegos e bebês que enxergam mostram que vários aspectos do desenvolvimento de bebês cegos podem sofrer atrasos a partir do segundo mês de vida, devido à função exercida pela visão na calibração dos sistemas proprioceptivo e vestibular (Prechtl et al., 2001). A ausência de visão teria como decorrência um atraso no desenvolvimento do controle da postura e dos movimentos. Ainda no âmbito do desenvolvimento motor, estudos anteriores, como o de Jan et al., (1975) descrevem a ocorrência de hipotonia durante os primeiros anos de vida em crianças cegas e apontam para a importância do estímulo ambiental e da experiência para superar essa condição. Reynell (1978) encontrou diferenças no desenvolvimento cognitivo de crianças com e sem deficiência visual nos primeiros anos de vida. Outros estudos destacam que as crianças cegas, principalmente aquelas cuja cegueira decorre de alterações no sistema nervoso central têm maior probabilidade de apresentar problemas de desenvolvimento no segundo ou terceiro ano de vida. Outro fator de risco é representado pelas condições sociais adversas a que muitas dessas crianças estão sujeitas (Cass et al., 1994). Vários dentre os estudos citados notam que os eventuais atrasos vão sendo compensados graças à plasticidade cerebral e à experiência, de modo que ao chegar à adolescência, o desenvolvimento se apresenta em geral como normal, a menos que a criança tenha sido privada de experiências sensoriais, motoras, cognitivas e sociais significativas. A maior parte dos estudos que abordam os diferentes aspectos do desenvolvimento (motricidade, cognição, linguagem, sociabilidade, personalidade, diferenças individuais) destaca também a importância dos estímulos do ambiente que, no caso da criança com deficiência visual, devem ser incrementados e adaptados o mais precocemente possível para promover o desenvolvimento (Warren, 1984).

Assim, se o contato visual com a criança não for possível, a mãe e os adultos em volta estabelecerão contato preferencialmente por meio 
Ver, não ver e aprender: a participação de crianças com baixa visão e cegueira na escola

do toque e da voz. O modo de embalar a criança, o tom de voz e os sons do ambiente ajudarão a construir as primeiras relações da criança com o mundo. Na medida em que a linguagem seja adquirida essas experiências serão investidas de sentido. O toque é um estímulo sensorial indispensável para o desenvolvimento. Assim, é importante lembrar que bebês com deficiência visual muitas vezes passam por internações hospitalares prolongadas no início da vida. Ambientes como a UTI neonatal seguem normas rígidas em relação à manipulação dos bebês e aos estímulos sensoriais permitidos. Mais recentemente, esse aspecto tem sido considerado nas rotinas hospitalares e alguns serviços de saúde já adotam a prática de estimular os bebês internados por meio da voz e do toque. Em contrapartida, é necessário considerar que as famílias de crianças com deficiência visual severa atravessam um processo difícil de aceitação e adaptação às condições que os bebês apresentam. Alguns estudos revelam que a frequiência de contato corporal entre mães de crianças com deficiência visual severa e seus bebês é menor que a freqüência de contato entre mães e bebês videntes (Freedman, 1971, 1975). Esses dados reforçam a idéia de que bebês com deficiência visual devem ser estimulados, tanto na função visual (por pequena que seja) como nas outras esferas do desenvolvimento.

A visão é uma função altamente motivadora para o desenvolvimento em todos os seus aspectos: os objetos, as pessoas, as formas, as cores e o movimento despertam curiosidade e interesse e incitam a criança a se aproximar e a explorar o mundo exterior. Crianças com baixa visão ou cegueira podem ter esse interesse diminuído pela falta de estímulos e podem, assim, tornar-se apáticas e quietas. Por isso, é preciso que o ambiente seja organizado para promover ativamente o desenvolvimento por meio dos canais sensoriais que a criança possui, de modo tal que ela seja capaz de participar nas atividades cotidianas e de aprender como qualquer criança. Se a visão é uma função importante, é preciso destacar, como o faz Vigotski (2000), que a sua ausência ou deficiência não impede o desenvolvimento, embora possa limitar, principalmente, a sua dimensão social. Para combater esse efeito (secundário) da deficiência visual é preciso investir de forma consciente e planejada na organização de um ambiente que promova a interação social e a participação dessas crianças. A linguagem é um dos meios privilegiados de promover a interação e a constituição de sentido e, à medida que a criança cresce e participa de vários ambientes sociais, a sua importância será crescente. 
O universo da criança se amplia consideravelmente quando ela ingressa na escola. Às relaçóes estabelecidas no ambiente familiar somamse novas relaçōes com adultos e com outras crianças. As características do funcionamento do sistema educacional fazem com que muitas vezes a dinâmica escolar interponha barreiras entre a criança com deficiência visual e o conhecimento. A estrutura que agrupa muitos alunos na mesma classe e privilegia aqueles com bom desempenho acadêmico dificulta a personalização do ensino e o atendimento dos que apresentam necessidades especiais. Contudo, quais são as necessidades dos alunos com deficiência visual?

\section{O uso de recursos ópticos, adaptaçóes do ambiente e tecnologia}

Os tipos de deficiência visual e as suas conseqüências para o desempenho visual da criança são muitos, assim como a etiologia das doenças que as causam e os recursos necessários para paliar seus efeitos. Enquanto um aluno pode precisar de iluminação especial, outro terá seu desempenho melhorado apenas mudando de lugar na sala de aula. Enquanto um aluno utilizará o sistema Braille de escrita outro poderá se valer de materiais em tipo ampliado ou de gravaçôes das aulas. É importante ressaltar que o uso de recursos específicos não será decidido apenas em virtude do tipo e grau de visão do aluno. Uma dimensão essencial dessa tomada de decisão é representada pela consideração de fatores relacionados à personalidade, modo de elaboração e estilo pessoal de cada criança ao lidar com a deficiência. Sacks (1997) relata o caso de três irmãos, na Noruega, que sendo portadores de uma rara doença genética (acromatopsia) apresentavam daltonismo (cegueira para as cores) associado a uma baixa acuidade visual. Inicialmente, a família foi aconselhada a inscrever o filho mais velho, Knut (e depois os outros), numa escola para cegos. Mas a criança não quis aprender Braille pelo toque. Ela usava a visão para ler os pontos em relevo e por isso foi castigada e forçada a usar uma venda nos olhos durante as aulas para impedir a visão. Depois, Knut fugiu da escola e aprendeu a ler sozinho em casa. Finalmente, foi permitido que ele freqüentasse uma escola comum. Apesar da doença, seguiu a carreira de cientista e se tornou fisiologista e psicofísico, pesquisador da visão na Universidade de Oslo. Knut, segundo o relato de Sacks, utiliza todo tipo de auxílio para desenvolver suas atividades. Durante a viagem que fizeram juntos às 
ilhas do Pacífico, Knut utilizara lupas, vários tipos de óculos e telescópio, além de aproximar os objetos quando necessário.

Britt, a irmã de Knut, teve um percurso totalmente diferente. Na escola para cegos, que Knut detestava, ela se desempenhou muito bem e se tornou proficiente em Braille. Britt trabalha na supervisão da transcrição e edição de livros em Braille na Biblioteca dos Cegos norueguesa. Ela também utiliza a visão, por exemplo, para realizar trabalhos de agulha com o auxílio de uma lupa acoplada aos óculos. O caso desses irmãos ilustra a influência das diferenças individuais na trajetória de vida, no modo de lidar com a deficiência e seus efeitos no desempenho escolar e profissional e na construção da identidade. A doença e a condição visual remetem a uma variedade de recursos que podem amenizar os problemas práticos, mas o que determina o tipo de recurso a ser adotado é a necessidade, interesse, disposição e objetivos do próprio sujeito, assim como as condições de inserção sociocultural e familiar que tornarão um recurso mais adequado ou viável que outro. Não há, portanto, uma conduta única que possa ser seguida em todos os casos, mas sim, estratégias de caráter geral que podem facilitar o trabalho escolar e derrubar barreiras de comunicação e acesso ao conhecimento.

Para começar é necessário prestar atenção ao uso que o aluno faz dos canais sensoriais que possui, sejam eles visuais, táteis ou auditivos, às suas características pessoais e à sua história de desenvolvimento e aprendizagem.

\section{Vítor}

Vítor, por exemplo, aos 10 anos de idade, nunca tinha freqüentado a escola. Morador de uma cidade do interior de um estado do Nordeste, era portador de uma doença ocular grave e apresentava baixa visão. A sua matrícula não foi aceita pela escola do bairro em que morava. Uma tia trouxe Vítor para morar com ela no estado de São Paulo e procurou atendimento oftalmológico e escolar. Vítor era uma criança inteligente e capaz de interagir com crianças e adultos, mas não dominava os conceitos que normalmente uma criança dessa idade adquire no decorrer do processo de escolarização nem havia desenvolvido a coordenação motora fina, por não ter realizado atividades que requeressem essa habilidade. À primeira vista, Vítor mostrava-se como uma criança muito 
tímida, com poucos recursos de sociabilidade, movimentos descoordenados, desconhecimento de letras, números e outros conceitos. Uma avaliação apressada que não levasse em consideração a sua história de vida poderia levar a interpretar o baixo desempenho de Vítor como um sinal de outros comprometimentos (mentais, por exemplo) associados à deficiência visual. Depois de alguns meses de inserção num programa para crianças com deficiência visual (Programa Deficiência Visual Infantil CEPRE/FCM/UNICAMP), onde pôde experimentar diversas atividades e entrar em contato com a leitura, a escrita e a matemática, Vítor passou a mostrar sua inteligência, capacidade de aprender e possibilidades de adquirir os conceitos e habilidades exigidos pela escola.

\section{Eduardo}

Como escolher um recurso para melhorar a participação do aluno na sala de aula se este não se reconhece como alguém que necessita de um recurso especial? Eduardo é um jovem que perdeu a visão aos 8 anos de idade. A transição para a cegueira foi gradual e acompanhada de grande angústia tanto para Eduardo como para a sua família. $\mathrm{Na}$ época da perda definitiva, Eduardo trombava com os móveis em casa e na escola e caía bastante, mas não aceitava ajuda e, quando interpelado, dizia que enxergava. Utilizou a visão até o último momento, quando apenas conseguia ver a cor de um objeto, sem distinguir a forma ou os detalhes.

Quando ainda utilizava materiais adaptados para baixa visão, Eduardo recusou-se a usar um caderno de pauta ampliada, no formato convencional (caderno grande, especialmente encadernado para esse objetivo). Pediu que as linhas mais largas fossem traçadas em caderno brochura, semelhante ao de seus colegas, foi atendido e isso lhe trouxe satisfação por reduzir diferenças em relação a seus colegas.

Gradualmente, Eduardo começou a utilizar o tato e o ouvido de forma crescente para se orientar no espaço e para conhecer o ambiente. Em seguida, aprendeu o sistema de escrita Braille. Como sabia ler e escrever, no seu caso, o Braille representou apenas o uso de um sistema de notação e leitura diferente, a transcrição do sistema de escrita alfabético para o Braille. Mais tarde, Eduardo começou a utilizar um computador com programas de voz. 


\section{Gláucia}

O uso de certos recursos como alguns tipos de óculos e telescópios requer cuidado e precisão. Uma criança pequena, ou muito inquieta, que não se concentra por um tempo razoável em qualquer atividade, terá dificuldades em se adaptar ao uso desses instrumentos. O recurso indicado para o problema de visão de Gláucia era um telescópio. Com ele, a menina poderia enxergar a lousa. O telescópio deveria ficar em cima da carteira e Gláucia deveria pegá-lo cuidadosamente, enfocar a lousa, ler o conteúdo e depositar novamente o telescópio na carteira para escrever. Porém, Gláucia era inquieta, agitada e se levantava toda hora do lugar. Além disso, não se concentrava nas atividades e vivia brincando com os colegas. Para que isso não ocorresse, a professora sentava-se ao lado da menina durante a realização das atividades escolares. Por isso, o uso do recurso foi adiado até que Gláucia adquirisse as competências necessárias para que o telescópio fosse útil a ela. Enquanto isso, ela se aproximava da lousa para copiar.

\section{Tiago}

O computador pode ser usado por crianças com baixa visão, com a ampliação das fontes e a mudança da configuração de cores da tela e também por crianças cegas, com a instalação de programas de voz que lêem o que está sendo escrito. Quando uma criança aprende a dominar os comandos básicos do computador, ela se encanta com o recurso e, muitas vezes, pede que a família adquira uma máquina para ela. Nesses casos, é preciso avaliar se as condições em casa e o grau de domínio do instrumento justificam a aquisição. Na escola, o uso do computador é geralmente monitorado por um professor e as condições técnicas de funcionamento são mantidas por pessoal especializado. Em geral, as crianças são usuários pouco qualificados que dominam apenas parcialmente os procedimentos e não podem solucionar problemas técnicos, caso estes surjam no decorrer do uso. Se não há na família ou no entorno social um adulto experiente que possa garantir condições adequadas de funcionamento, a aquisição do equipamento não será útil. Quando Tiago, um menino cego que aprendeu a utilizar o computador para escrever e jogar pediu o equipamento, sua mãe fez um curso de informática para poder assistir o filho. Somente depois que ela teve 
um domínio maior que o de Tiago dos modos de uso é que o computador foi adquirido.

Os exemplos de trajetórias de crianças mostram a necessária diversidade de fatores que devem ser levados em consideração para prover, em cada caso, os recursos e estratégias que auxiliarão a participação na escola. Essa avaliação deve ser realizada no contexto da própria escola, do atendimento especializado ou de outros equipamentos de apoio à inclusão.

Práticas que favorecem a participação de crianças com deficiência visual

Como favorecer a participação da criança com deficiência visual nas atividades escolares? Os exemplos acima citados, envolvendo crianças com diferentes níveis de dificuldade visual e, mais que isso, com diferentes histórias de vida, explicitam a necessidade de levar em conta, de forma abrangente e dinâmica, os múltiplos aspectos envolvidos no processo de escolarização.

No que se refere ao desenvolvimento e à aprendizagem, a idéia de que eles ocorrem por meio das interações entre a criança e pessoas significativas para ela, sejam adultos ou outras crianças, dá destaque à dimensão social envolvida no ato de ensinar, visto, de acordo com Coll e Solé (1996), como um processo contínuo de negociação de significados, que ocorrem ao longo das interações em grupo. Destaca-se, assim, a importância da atuação em grupo, da mesma forma que Coll e Colomina (1996), autores que valorizam o contato entre as crianças e seus parceiros, em situações cooperativas, para favorecer a aprendizagem.

Dessa forma, atividades grupais de ensino e recreativas, envolvendo diferentes recursos pedagógicos, vêm sendo propostas em situaçôes de ensino formal e informal, iniciando-se na pré-escola. É de se destacar que, nas fases iniciais do processo, é bastante comum o uso freqüente de recursos visuais (objetos, figuras, imagens) que, muitas vezes, dificultam a inclusão de crianças com deficiência visual. A carência de material adaptado para essa fase do ensino foi destacada por Preisler (1997), em um estudo longitudinal em que dez crianças cegas suecas foram acompanhadas desde o nascimento até os 6 anos de idade, com uma nova observação aos 10 anos. Em seu estudo, a autora 
considerou que as principais dificuldades observadas ao longo do processo de inclusão escolar se referiram ao desenvolvimento social das crianças. Aos 10 anos, Preisler verificou que as crianças acompanhavam o currículo escolar e se utilizavam dos recursos da informática para as atividades escolares. Observou, inclusive, que, devido ao desenvolvimento tecnológico, elas não tinham mais a necessidade de carregar pesados livros em Braille, transportando, apenas, disquetes de computador, no trajeto entre a casa e a escola. Contudo, descreveu o isolamento social dessas crianças, especialmente no período pré-escolar, comentando sobre a ausência de material pedagógico e lúdico adaptado, que permitisse a atividade conjunta. No que se refere ao ensino formal, o atendimento mais individualizado propiciou um aprendizado de conteúdos equivalente ao das crianças videntes. Mas as interações entre cada criança cega e seus parceiros videntes, em termos de brincadeiras e atividades grupais de ensino, ao longo da pré-escola, ficaram bastante prejudicadas pela falta de material para uso conjunto, acessível a todas as crianças.

Por isso, entendemos que uma das práticas que devem ser valorizadas nos contextos de educação formal e não-formal é o oferecimento de recursos que propiciem a atividade conjunta de crianças com diferentes dificuldades visuais e, por extensão, de crianças sem alterações visuais. Embora essa pareça ser uma afirmação trivial, é interessante lembrar que existem materiais desenvolvidos exclusivamente para cegos (ex: livros de história escritos em Braille e ilustrados com figuras reconhecíveis por seu contorno em relevo, em papel monocromático, portanto de difícil identificação por uma criança com baixa visão, ou mesmo por um professor ou um adulto vidente), enquanto outros são desenvolvidos especificamente para crianças com baixa visão (portanto, não acessíveis a crianças cegas).

Pensamos que, sempre que possível, especialmente nas atividades em grupo, devemos incorporar a idéia do desenho universal, tal como vem sendo preconizado pelos autores que discutem acessibilidade. Neste sentido, serão descritas e comentadas, a seguir, algumas experiências de elaboração e utilização de recursos, em duas modalidades: a) materiais mais estruturados e fixos, tais como tabuleiros de jogos e livros ilustrados; b) materiais para realização de projetos temáticos, tais como os necessários para desenho e/ou confecção de componentes para uma brincadeira em elaboração (ex: talôes de cheque, bingos criados pelo grupo etc.). 


\section{a) Materiais mais estruturados e fixos}

No que se refere aos materiais mais estruturados, é necessário que tragam a informação de modo a ser reconhecida de forma tátil e visual. Essa exigência traz alguns desafios, pela necessidade de dispor, em um espaço limitado, informaçôes táteis e visuais equivalentes, oferecendo, ao mesmo tempo, um material "claro" e "não poluído".

\section{Jogos de bingo}

Um dos exemplos de adaptação envolve o jogo de bingo, que permite o trabalho com diferentes conceitos, com material a ser pareado por identidade (ex: formas ou números iguais no cartão sorteado e nas cartelas) ou relação entre atributos (ex: parte-todo, espécie e gênero, figura e palavra ou ícone correspondente). Em um exemplo de adaptação de um bingo de formas, essas foram desenhadas em material tateável e coladas sobre cada cartela e também em pequenos cartões, a serem sorteados. Vários tipos de materiais podem ser utilizados para preparar figuras em relevo, como é descrito com detalhe por Reily (2004). Um outro detalhe: foi delimitado, na cartela, um lugar para colocar o marcador da figura já sorteada (como os feijóes no bingo tradicional), reduzindo o risco de serem deslocados, no momento da colocação de novos marcadores, relativos a novas figuras sorteadas. Isso foi feito com o recorte de orifícios quadrados na cartela, em posição fixa em relação a cada forma, colando-se o conjunto todo sobre outra cartolina. Os "feijōes", ou peças para marcar figuras sorteadas, eram quadrados de $\mathrm{EVA}^{1}$ que se encaixavam nos orifícios. Isso permitiu muitas jogadas, bastante animadas, sem a perda da informação sobre as figuras já sorteadas para cada participante.

\section{Dominó}

Outro jogo que permite o pareamento, de forma conceitualmente semelhante ao bingo, é o dominó. Entretanto, algumas dificuldades foram observadas com um dominó adaptado, confeccionado em madeira, com orifícios no lugar das bolinhas tradicionais: era difícil para as crianças compreenderem o conjunto que ia se formando e detectarem a configuração das extremidades (informação relevante para sua jogada), sem 
tirar as peças do lugar. Nesse aspecto, no caso da cartela do bingo, há maior espaço para manuseio e aproximação da criança e para assistência individualizada, sem o risco de perda de informaçôes do jogo coletivo, como ocorre quando o desenho do dominó é parcialmente desfeito por movimentos bruscos de um participante. Entretanto, dependendo das características do grupo de crianças, o jogo de dominó constitui uma alternativa interessante.

\section{Jogos de tabuleiro}

Outra modalidade de material que permite adaptações é o jogo de tabuleiro. Um exemplo que criamos foi o do jogo "Cidade-bosque", com 20 casas a serem percorridas. Essas casas eram formadas por quadrados de EVA: as de número par, em vermelho, expondo a parte rugosa do material, e as ímpares, em amarelo, expondo a parte lisa do material. Cada casa era numerada de duas formas: com os números convencionais, escritos com tinta preta em tamanho grande, e com números em Braille, feitos com rebites de metal inseridos no EVA. Os "carros" eram pequenos retângulos, com cores e texturas variadas, e o dado, em modelo convencional, tinha as bolinhas salientes, reconhecíveis, portanto, tanto pela visão como pelo tato. Observou-se que grupos de crianças, com diferentes níveis de dificuldade visual, participaram de jogos em condições semelhantes para a identificação das informações relevantes. As dificuldades observadas foram de outra ordem, caracterizando o contato inicial com uma nova modalidade de tarefa (envolvendo noção de correspondência e de contagem, noção de regras do jogo, entre outras), mas não de identificação das informações do tabuleiro.

Outra experiência com jogos de tabuleiro referiu-se ao jogo de damas produzido pela American Foundation for the Blind. O tabuleiro é confeccionado em material plástico, em tom azul-claro, com reentrâncias para cada casela. As peças são vermelhas e pretas e se distinguem também pelo formato (quadradas e redondas). Encaixam-se bem, permitindo compor e fixar a "dama". Ao utilizar o jogo com duas crianças, Marina (cega) e Pedro (baixa visão), considerou-se que seria melhor sinalizar o tabuleiro, pintando de preto as caselas pretas do tabuleiro original e deixando as "brancas" na cor do plástico. Essa medida facilitou a compreensão das regras para movimentação das peças por Pedro, que era mais velho que Marina e apresentava dificuldades de 
aprendizagem em várias tarefas escolares. Marina aprendeu mais rapidamente que Pedro as regras do jogo, não sugerindo a necessidade de marcação, por meios táteis, dos quadrados pretos e brancos do tabuleiro. Possivelmente, isso seria necessário para outra criança. Essa observação ilustra a idéia de que não existe uma única solução para adaptação de materiais: trata-se de uma questão dinâmica, a ser definida no contexto da utilização desses materiais.

\section{Livros ilustrados}

Uma experiência interessante envolveu a confecção de livros infantis, para um projeto de contação de histórias, realizado por Solovijovas e Batista (2003). Foram escolhidas quatro histórias infantis, usualmente utilizadas em projetos educacionais, e confeccionados os livros adaptados, com o texto em tipo ampliado, em letra de forma, de modo a favorecer a leitura por crianças com baixa visão, ${ }^{2}$ com o texto em Braille correspondendo ao texto em tinta. Para as ilustrações, decidiu-se que não se buscaria uma representação de cada uma das figuras dos livros originais. Foram selecionadas imagens representativas das principais cenas das histórias, em geral modificadas de forma a não representar a cena toda, mas sim poucos personagens ou elementos significativos. Estes foram caracterizados por figuras montadas com diferentes recursos: EVA, tecido, lã (ex: as ovelhas eram feitas em lã costurada), contas (costuradas) para indicar olhos e outros detalhes, objetos miniatura. Observou-se a exploração das figuras e o tateio do texto, pelas crianças, com diferentes níveis de participação e semelhantes aos observados por crianças videntes, nos diferentes momentos de contato com o livro infantil.

No que se refere à representação de figuras e cenas, é importante lembrar que não se trata de "traduzir" uma representação visual em seu correspondente tátil. Gravuras são o resultado de séculos de história da arte, de soluções estéticas e representativas que envolvem perspectiva, gradação de tons e diferentes modos de indicar formas e volumes. É possível e desafiador criar uma representação tátil, a partir da mesma temática que sugeriu uma representação visual (por exemplo, o texto de uma história infantil). Abre-se, assim, uma perspectiva pouco explorada até o presente, que transcende, em muito, a mera adaptação de material gráfico. 
Os exemplos citados mostram a viabilidade de criação de materiais que permitam a participação conjunta em atividades educacionais e lúdicas de crianças com e sem deficiência visual, em situaçôes que, usualmente, são centradas em materiais que exigem a visão. É importante, entretanto, não reduzir a questão à elaboração de um acervo de materiais adaptados. É sempre importante estar atento à dinâmica de utilização dos mesmos, relacionada aos interesses e competências dos membros dos grupos, propondo renovação e readaptação dos recursos.

\section{b) Materiais para realização de projetos temáticos}

Quanto aos materiais para utilização em projetos temáticos, a questão central se refere à sustentação da participação das crianças com deficiência visual, em projetos para os quais o professor só está preparado para lidar com base em recursos visuais.

Como exemplo de soluções que temos explorado, relatamos uma brincadeira de faz-de-conta com o tema "escritório". Uma das atividades propostas envolvia a utilização de talóes de cheque. As crianças, então, confeccionaram seus próprios talóes, por meio de diferentes recursos: texto em Braille, texto em tinta com caneta hidrocor de alto contraste ou com caneta comum, reproduzindo a configuração de um cheque com diferentes graus de detalhe, desde a escrita convencional até traços imitando a escrita.

Outros exemplos foram observados ao longo de um projeto sobre meios de transporte (Silva, 2007). Entre as atividades desenvolvidas para a compreensão dos diferentes meios de transporte em uma cidade, foi montada uma maquete, composta por casas, carros e ônibus. A confecção desses itens foi feita pelas crianças, com orientação dos adultos, utilizando moldes em papel e cartolina, lápis e canetas de diversos tipos. Foram confeccionados bonecos em massa, para representar as pessoas, e montados semáforos. Os carros, também em cartolina, tinham rodas em EVA. A cena foi montada sobre uma grande folha de cartolina, na qual estavam traçadas ruas, indicadas por traços visíveis e em relevo. Em outro momento, além da montagem da cidade, foi simulado um lago (uma caixa plástica com água, com o entorno simulando uma colina), no qual foram colocados barcos de papel, também confeccionados junto com as crianças. 
Outra atividade realizada foi a da explicação da flutuação. Foi utilizada uma bacia grande com água e, com a participação de todos do grupo, diferentes materiais foram colocados para verificar suas características de flutuação. As conclusões foram aplicadas à compreensão da flutuação dos barcos.

Quando da explicação dos trilhos do trem, foi montado um modelo de trilho (cartolina e madeira) e um conjunto de duas rodas de trem ligadas por um eixo (em cartolina), de forma a explicar como a roda se encaixa no trilho. As crianças foram encorajadas a manusear essas rodas sobre o trilho e foram feitos comentários sobre o que significa o descarrilamento de um trem, com base no desenho animado que tinha sido exibido e explicado ( $O$ Expresso Polar).

\section{Considerações finais}

O sucesso escolar de alunos com deficiência visual é um dos desafios da inclusão. Embora, de acordo com os teóricos do desenvolvimento, a deficiência visual em si não constitua um obstáculo necessário para o desenvolvimento e para a aquisição de conhecimento, a trajetória escolar de muitas crianças com deficiência visual acaba sendo mal-sucedida devido a um conjunto de fatores que envolvem desde os serviços de detecção e a intervenção precoce, incluindo-se, aí, a assistência à criança e a orientação à família, até a instrumentalização dos professores para utilizar, com cada faixa etária e com cada criança, os recursos que promovam o interesse e a participação plena nas atividades da escola. $\mathrm{O}$ trabalho orientado nessa direção deve integrar conhecimentos sobre desenvolvimento, aprendizagem e necessidades específicas desse grupo, assim como informações sobre o estilo pessoal de cada aluno e sobre o comportamento do grupo em que está inserido. Os exemplos de confecção e uso de materiais acessíveis em atividades concretas e projetos de ensino remetem ao conjunto de informaçôes que constitui a base sobre a qual as estratégias pedagógicas serão construídas, utilizando-se recursos específicos, materiais diversos e pequenas adaptações, segundo a necessidade. $\mathrm{O}$ foco na dimensão social da aprendizagem, aliado à remoção de barreiras e às estratégias que favoreçam o uso coletivo de materiais e a cooperação, permitirá ao professor utilizar recursos tateáveis/visuais/auditivos e organizar a sala de aula de modo que ela seja acessível a todos os alunos. É interessante lembrar aqui que nem sempre as estratégias de ensino 
Ver, não ver e aprender: a participação de crianças com baixa visão e cegueira na escola

requerem recursos especiais, mas sempre exigem a presença de um professor atento, informado e dinâmico, capaz de identificar, a cada momento, as necessidades dos seus alunos.

Recebido em março de 2008 e aprovado em julho de 2008.

\section{Notas}

1. Borracha não-tóxica produzida a partir de uma mistura de alta tecnologia de etil, vinil e acetato.

2. É sempre importante lembrar que a baixa visão não constitui um quadro único: há variações na acuidade, campo visual, visão de contraste, adaptação à luz e ao escuro, podendo essas dificuldades serem únicas ou estarem combinadas, com diferentes graus de severidade. Assim, não se pode falar em material adaptado, de forma generalizada. Entretanto, convencionou-se que será mais provável o reconhecimento de textos e figuras ampliados, com alto grau de contraste (contornos de letras e formas, cores no preenchimento de figuras), e sem brilho excessivo.

\section{Referências}

BRUNER, J. Atos de significado. Porto Alegre: Artes Médicas, 1997.

CARVALHO, K.M.M. et al. Visão subnormal - orientações ao professor do ensino regular. Campinas: Editora da UNICAMP, 1992.

CASS, H.; SONKSEN, P.M.; McCONACHIE, H.R. Developmental setback in severe visual impairment. Archives of Disease in Childhood, v. 70, p. 192-196, 1994.

COLL, C.; COLOMINA, R. Interação entre alunos e aprendizagem escolar. In: Coll, C.; Palacios, J.; Marchesi, A. (Org.). Desenvolvimento psicológico e educação. v. 2 - Psicologia da Educação. Trad. de A. M. Alves. Porto Alegre: Artes Médicas, 1996. p. 298-314.

COLL, C.; SOLÉ, I. A interação professor-aluno no processo de ensino e aprendizagem. In: Coll, C.; Palacios, J.; Marchesi, A. (Org.). Desenvolvimento psicológico e educação. v. 2 - Psicologia da Educação. Trad. de A. M. Alves. Porto Alegre: Artes Médicas, 1996. p. 281-297.

FREEDMAN, D.A. Congenital and perinatal sensory deprivation: some studies in early development. American Journal of Psychiatry, v. 127, p. 115-121, 1971. 
FREEDMAN, D.A. Congenital and perinatal sensory deprivations: their effect on the capacity to experience affect. Psychoanalytic Quarterly, v. 44, p. 62-80, 1975.

PRECHTL, H.F.R. et al. Role of vision on early motor development: lessons from the blind. Developmental Medicine \& Child Neurology, v. 43, p. 198-201, 2001.

JAN, J.E. et al. Hipotonia in the blind child. Developmental Medicine and Child Neurology, v. 17, p. 35-40, 1975.

PREISLER, G. Social and emotional development of blind children: a longitudinal study. In: LEWIs, V.; Collis, G.M. (Org.). Blindness and psychological development in young children. Londres: The British Psychological Society, 1997. p. 69-85.

REILY, L. Escola inclusiva: linguagem e mediação. Campinas: Papirus, 2004. (Série Educação Especial).

REYNELL, J. Developmental patterns of visually handicapped children. Child Care, Health and Development, v. 4, n. 5, p. 291-303, 1978.

SACKS, O. A ilha dos daltônicos. São Paulo: Cia das Letras, 1997.

SILVA, F.C.P. A formação de conceitos em crianças. Projeto de Iniciação Científica, Bolsas SAE - UNICAMP, seleção PIBIC/CNPq, ago. 2006/jul. 2007.

SOLOVIJOVAS, A.R.; BATISTA, C.G. A importância da adaptação de livros infantis e da contação de histórias para crianças com deficiência visual. I Congresso Brasileiro de Educação Especial, I Encontro da Associação Brasileira de Pesquisadores em Educação Especial e IX Ciclo de Estudos sobre Deficiência Mental, Anais..., Sessão 18 de Comunicações Orais, p. 72-73, 2003.

VEITZMAN, S. Visão subnormal. Rio de Janeiro: Cultura Médica, 2000. (Coleção de Manuais Básicos СвO).

VIGOTSKI, L.S. A formação social da mente. São Paulo: Martins Fontes, 1984.

VIGOTSKI, L.S. Obras escogidas. Madrid: Visor, 2000.

WARREN, D.H. Blindness and early childhood development. 2. ed. rev. New York: American Foundation for the Blind, 1984. 